\title{
Validation of Mentor's Behavior Scale among mentors
}

Rong Zhao ${ }^{\mathrm{a}}$, Roger Watson ${ }^{\mathrm{b}}$, Yanhua Chen ${ }^{\mathrm{c}}$

Rong Zhao, MA, RN, the third people's hospital in Chengdu, 646000,

China email:350458903 @ qq.com,

Roger Watson PhD, RN, Professor, University of Hull ,United kingdom

Yanhua Chen, $\mathrm{PhD}, \mathrm{RN}$, Associate Professor, infectious disease

department of the Affiliated Hospital of Southwest Medical University,

646000,China

Word count: 3430

(C) 2018. This manuscript version is made available under the CC-BY-NC-ND 4.0 license http://creativecommons.org/licenses/by-nc-nd/4.0/ 
*Manuscript (without Title Page)
Click here to view linked References

Validation of Mentor's Behavior Scale among mentors

Validation of Mentor's Behavior Scale among mentors

(1)

s

(1)

(n)

(1)

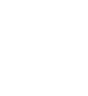

(n)

.

.

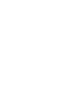

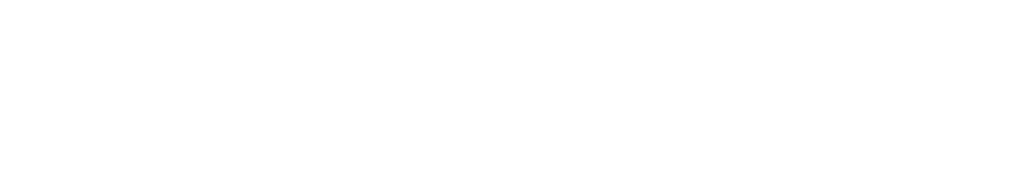

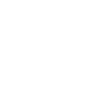

(1)

(1)

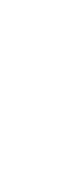


Background: The Mentor's Behavior Scale was developed and validated initially among nursing students by assessing the importance of mentors' behaviour, showing satisfactory psychometrics and the potential to match mentors with students according to students' expectation.

Objectives: This study aims to test the discriminant validity and the structure of the Mentor's Behavior Scale among mentors to assess mentors' performance.

Design: A cross-sectional survey was applied in the study.

Setting: Data were collected from mentors in seven hospitals in north, south, southwest China in 2016 and 2017.

Participant: 871 mentors participated in this study.

Methods: Purposeful sampling and online survey was used.

Results: Three factors (to guide personal growth, promote professional development, and provide psychosocial support) were identified by exploratory factor analysis. The cumulative contribution of variance was $61.03 \%$. The Cronbach's alpha coefficient of the scale was 0.85 , and those of the three subscale's were $0.84,0.72$, and 0.74 . The results of discriminant validity showed that mentors who received training and who liked mentoring students scored higher in mentoring behavior.

Conclusion: Mentors considered that mentoring behavior were to guide students' personal growth, promote professional development and provide them with psychosocial support. It will be useful to apply The Mentor's Behavior Scale among mentors to guide and evaluate their behaviors. 
Key words: nursing; mentors' behavior; validity; reliability; education 


\section{Highlights}

-A three-dimensional mentor's behaviour model (to guide personal growth, promote professional development, and provide psychosocial support) was identified among mentors.

- This study showed the potential that the Mentor's BehaviorScalecould be used among mentors to guide and assess their performance.

- The MBS scale showsthe ability to distinguish different level ofmentoring performance. 


\section{Introduction}

Mentorship has been adopted in clinical nursing education in China, but it is developing relatively slower than that of western countries (Chen et al, 2016). Mentors may not perform properly as educators to support, guide and assess nursing students (Eddins et al., 2011). Studies (Heet al., 2011; Yiet al., 2013) report that some nursing students lost their interests in nursing during their time in clinical placement. The reasons include reality shock, negative experience, such as being tense with patients, lack of confidence in skills and knowledge and not being clear about professional prospects. These difficulties suppose to be managed successfully, given ideal mentorship. Therefore, it is necessary for mentors to understand how they should behave to improve the quality of mentorship.

\section{Background}

To guide, standardize and evaluate the behavior of mentors in China, a suitable instrument is essential. The Mentor's Behavior Scale (MBS) was developed through a literature review and online focus group interview by the research group in 2014 and was validated in Chinese Nursing Students (Chen et al, 2016; Chen et al, 2018). The students were asked to measure the importance of each behavior and the results showed a three-factor structure: promoting professional development, facilitating learning and psychosocial support, satisfactory psychometrics and the potential to match mentors with students according to students' expectation using the MBS. The 
structure of this scale was confirmed later in nursing students by asking them the performance of their mentors using confirmatory factor analysis (Chen et al, 2018).However, further validation is necessary to apply this scale among mentors to guide and assess their own performance and to diagnose the weakness and find the training needs. The reason is that the population mentor might be different from students and they may perceive mentorship variously and the psychometrics of a scale is relevant to the population it is tested (Streiner and Norman, 2008).

Therefore, a study aimed to validate the mentors' behaviour scale among mentors to provide the potential of this scale to be used by mentors to guide and evaluate their mentoring behavior was carried out. It showed that the content validity index of MBS among mentors was 0.91 , the test-retest reliability was 0.89 (ICC $=0.89$ ). Three factors (guiding personal growth, professional development, psychosocial support) including 23 items were identified, explaining $50.99 \%$ of total variance and published in a Chinese journal (Zhao et al, 2017). While the variance explained was low, other validity, such as discriminant validity was not reported. This study aims to verify the discriminant validity and to obtain a simplified and stable structure using an enlarged sample size.

\section{Methods}

3. 1. Design

A cross-sectional study using an online survey was employed.

\section{2 Instrument}


The MBS was used in this study, which followed a three-dimensional model of mentor's behavior generated through a literature review. The development and validation among nursing students were reported by Chen (2016). In a previous study, A three-dimensional model of mentors' behavior (professional development, psychosocial support and facilitating learning) was identified through exploratory factor analysis and Mokken scale analysis and confirmed among nursing students. (Chen et al. ,2016, Chen et al, 2018).

\section{3. Participants and data collection}

Purposeful sampling was used and 858 mentors from hospitals in Beijing, Shenzhen, Kunming, Sichuan representing mentors in north, west and south of China completed an online survey to explore the structure of mentors' behavior. Questionnaires were selected through the Questionnaire Star, a Chinese online survey tool. In each hospital, there was a research cooperator and they sent internet link to head nurses and then the head nurses sent it to mentors on wards. Each device (cell phone, computer) or each account is allowed only to complete one questionnaire. Mentors were asked to rate the frequency with which they performed the mentoring behaviour and they responded on a 5-point Likert scale (1-5) from 'never' to 'always'. The selection criterion of mentors was that they must have more than one years' experience of continuous mentoring nursing students.

According to the requirements of exploratory factor analysis, the sample should not 
be less than 430 (Ferguson and Cox,1993). In this study, 871mentors responded. The time of completing the questionnaire was monitored and those taking less than 3 minutes were excluded as these were considered to lack motivation to complete the questionnaire carefully. In total, 13 cases were excluded and 858questionnaires were entered into the data analysis.

\section{4 Data Analysis}

The data was at first analyzed using descriptive statistics. Data distribution was tested for normality and homoscedasticity, using the Kolmogorov-Smirnov and Levene tests, respectively. The tests revealed a normal distribution of the data. The construct validity of the instrument was analyzed using explorative factor analysis and the reliability of each of the sub-dimensions was analyzed using Cronbach's alpha coefficient. The discriminant validity was calculated by using ANOVA and independent sample $t$ test. SPSS 22. 0was used in data analysis.

\section{5 Ethics}

The study was approved by the ethics committee of the Affiliated Hospital of Southwest Medical University in China and permission was acquired from seven hospitals in China. Consent statement was explained to participants before they completed the questionnaires that their information could not subsequently be withdrawn but that the confidentiality was protected. No personal information was 
collected.

\section{Results}

4. 1Demographic Information

The demographic information of mentors participated in the survey is shown in Table 1. The majority of them were female $849(98.95 \%)$ and the age ranges from 23 to 54 $(31.57 \pm 7.18)$ years old

\section{2 Structure of mentors' behaviour among mentors}

The exploratory factor analysis results show that the initial sampling suitability KMO value was 0.97 and Bartlett 's spherical test value $\operatorname{was}^{2}(903)=17207.67,(\mathrm{p}<0$. 001)both indicated the correlation coefficients among all the items are large enough to do EFA ( Wu, 2010). Principal component analysis (PCA) was selected for this study. Because the number of items was over 40 and some communalities were below 0 . 4,based on eigen values $>1$, there were 6 factors, which probably overestimated the number of factors (Field, 2009). While the scree plot showed that there might be three or four factors. Under this condition, Monte Carlo parallel analysis for Principal Component Analysis (MCPA) was used to decide the number of factors to extract. Finally, three factors were decided. Both orthogonal rotation and oblique rotation were tried. The orthogonal rotation gave a simpler solution and the correlation coefficient between the factors was less than 0.3 . Accordingly, varimax rotation was selected in this study. Items that met the following conditions would be deleted one by 
one: items with loading below 0.6 , cross loading over 0.4 , and the absolute value difference between two maximum cross loading $<0.2$. This process was repeated until a simple structure appeared where loadings were maximized on presumptive factors and minimized on the others.

Principal component analysis was carried out on 43 items (The questionnaire had originally 46 items, and three items were deleted after content validity analysis (Zhao, et la, 2017) with varimax rotation. A three-factor structure with 12 items (four items four each factor) was identified, explaining $61.03 \%$ of the variance. The three factors were named as: Guide Personal Growth (GPG), Professional Development (PD), and Psychosocial Support (PS), according to their contents. Eigenvalue and percentage of explained common variance are shown in Table 2 . The communality and factor loading matrix is shown in Table 3. The scree plot is shown in Figure 1.

\section{3 Internal Consistency Reliability}

The Cronbach alpha coefficient of the total scale was 0.85 and those of the three subscales were $0.84,0.72$, and 0.74 , respectively.

\section{4 Discriminant Validity}

Comparing the difference in scores between groups having mentorship training experience or not, and attitude towards mentoring students, the results showed that the score of trained group was higher and the scores of groups holding different levels of favoring mentorship differed (Table 4). 


\section{Discussion}

This cross-sectional study showed an identical structure of MBS identified in the previous study (Zhao et al, 2017) and tested the discriminant validity among mentors, while this study revealed a model with 12 items, which explained more variance (61\%) than in a previous study.

While the structure model is not consistent completely with that observed in nursing students, with two same factors: to promote professional development, psychosocial support and one different factor: to guide personal growth instead of to facilitate learning (Chen et al, 2016, Chen et al, 2018). This may be due to the reason that students and mentors perceive mentorship slightly different from each other as psychometrics is closely related to the population tested instead of intrinsic property of a measurement tool (Streiner and Norman, 2008). Mentors may consider mentorship based on a one-to- one relationship, individualized teaching model, therefore to lead students' individual development and growth is an inseparable part of their responsibility. But students may think more about learning, expecting mentors could help with their study, as they are under the pressure of passing all sorts of exams, which may have not much influence over mentors.

Factor 1- Guide Personal Growth including concepts, for instance, personal development, discussing learning goals, stimulating students' potential. The factor reflects that mentors attach importance to the students' individualized education in the "one-to-one" teaching process and take guiding students' personal growth as an 
important aspect of mentoring. Usually, nursing students in China are at the early adult transition stage (17-22 years old), and the structure of their lives are undergoing rapid change. They are moving away from adolescence and family life, and need to build new relationships with patients, mentors and other staff in clinical practice. In addition, the pressure of employment and how to deal with the various relationships in their future work independently are also imposed on them. They may feel anxiety and pressure due to ill-preparation for the new adult world (Levinson, 1986). As a "one-to-one" instructor, a mentor has a close relationship with students, understands students' problems and needs, and knows more about the prospects of the nursing. According to the characteristics of students, mentors set individualized learning goals with students, adopt appropriate teaching methods, which can stimulate enthusiasm and improve effects of learning and contribute to personal growth of students (Zhou, 2009).

Critical thinking scores the lowest in this study, as in Chen's (2016) study. Critical thinking is unanimously recognized as a necessary thinking skill that a nurse should have in data appraisal, analysis and patient care decision-making (Sullivan, 2012). The results suggest that proper guidance and training are imperative (Sullivan, 2012).

Factor 2-Professional Development accounts including concepts such as showing decision making in nursing, encouraging evidence-based practice, the legal issues involved in nursing, giving student an objective and comprehensive evaluation. This factor exists both in the validation of students and in mentors, which suggest clinical practice is a key transitional period from a student to a nurse. Mentors play a pivotal role to make this transition smoothly, that is to say to improve students' professional 
development. But in students' sample, the item" to show a positive image" had the heist loading on the factor (Chen et al, 2016), while in mentors the item "show student how to make decisions on patient care" shared the largest loading. The difference may suggest that mentors are experienced in nursing and perceive that the essence of nursing care is to make proper decision, while students are new to nursing real picture and are incline to be influenced by negative image and behaviour presented by their mentors, and they need positive encouragement to take nursing role as their specialty in the future.

In clinical mentoring, mentors promote the professional development of nursing students by imparting important knowledge and skills in nursing work. Other studies have also emphasized that clinical teachers should have a high level of professional competence (Wang 2013;Gonget al,2003;Knox 1985), but this factor has the lowest scores in this survey, especially for the item 'evidence-based practice'. Some research and training programs should be conducted to enhance mentors' knowledge and skills about it (Wallen et al., 2010)

Factor 3-Psychosocial support includes concepts about being warm and friendly, respect, support and encouragement, role model for students, possessing the highest mean scores. Trust and respect from mentors and being a good role model for students could help students try to imitate the mentor's behavior in mentorship (role modeling) and can then enhance their expertise (Wanberg et al,2003). In addition, it would facilitate the mentee's adaptation to nursing jobs and nursing environments (Weng et 
al, 2010).

This factor has been identified both in nursing students and mentors, but there is some inconsistency. As for students the item "to be treated as a learner other than free human power" was selected to be the first one of this factor (Chen et al, 2016). However, this item was not endorsed highly by mentors; instead the item "to be friendly and warm with students" was the most highly endorsed. This may due to mentors and students valuing different behaviours or the questions asked are different between students and mentors: in students, the importance of behaviour was asked (Chen,et al 2016) while in this study among mentors the frequency of their mentoring behavior was questioned.

The total reliability of the study scale and the three factors were all greater than 0.7 , indicating that the scale and the three facets have good homogeneity, the extracted factor structure was reliable, and the correlation between all items was good.

The results of discriminant validity showed that mentors who have received training and who likes mentoring students have higher scores, suggesting that the scale can detect different levels of mentoring performance, particularly according to mentors'different extents of liking mentoring students. This reveals that education administrators should consider the mentor's attitude towards mentoring when selecting mentors besides clinical competence. At the same time, the specially 
designed mentor program helps to lead to a more positive attitude towards mentoring and a positive effect on mentor functioning is pivotal (Smedley, 2010).

\section{Conclusion}

The Mentors' Behavior Scale showed the three-factor behaviour structure has been observed. This study expanded the use of MBS from rating nursing students expectation of mentorship to assessing mentoring performance by mentors themselves and provided the possibility to use the MBS among mentors to guide and assess their behaviours.

\section{Conflict of Interests}

None declared.

\section{Funding}

No special source of funding. 


\section{References}

Chen, Y. , Watson, R. , Hilton, A. , 2016. An exploration of the structure of mentors' behavior in nursing educationusing exploratory factor analysis and Mokken scale analysis. Nurse Education Today. 40,(161-167).

Chen Y, Watson R, Hilton A. , 2018. The structure of mentors' behaviour in clinical nursing education: Confirmatory factor analysis. Nurse Education Today. Jun 26;68:192-197.

Chen, Y. H. , 2016. Developing and validating a scale to study mentors'behaviour in nursing education (Unpublished doctor's thesis). University of Hull, Hull, UK.

Eddins, E. E. , Hu ,J. , Liu, H. , 2011. Baccalaureate nursing education in China: issues and challenges. Nursing Education Perspectives. 32(1),30-33.

Field, A. , 2009. Discovering statistics using SPSS. third ed. Sage publications, London.

Gong, Y. H. , Wang, Y. , Lu, H. , \& Zheng, X. ,2003, A survey of effective teaching behaviors of clinical teachers. Chinese Journal of Nursing, 38(1), 10-13(Chinese language journal).

He, J. Y. , Jiang, X. Y. Jin, S. ,2011. A survey on the attitude towards employment in undergraduate nursing students. Journal of Chinese Nursing Management. 11(7), 75-77(Chinese language journal).

Knox, J. E. ,\&Mogan, J. (1985). Important clinical teacherbehaviours as perceived by 
university nursing faculty, students and graduates. Journal of Advanced Nursing, 10(1), 25-30.

Levinson, D. J. , 1986. A conception of adult development. American Psychologist. 41(1), 3-13.

Smedley A, Morey P, Race P. ,2010. Enhancing the knowledge, attitudes, and skills of preceptors: an Australian perspective. Journal of Continuing Education in Nursing, 41(10):451.

Streiner, D. L. , Norman, G. R. , 2008. Health measurement scales: A practical guide to their development and use. fourth ed. Oxford University Press, Oxford.

Sullivan E A. , 2012. Critical thinking in clinical nurse education: Application of Paul's model of critical thinking. Nurse Education in Practice, 12(6):322-7.

Yi,Y. M. N. ,Qiu,H. L. ,Liu,L. ,Li,J. N. ,Liang,T. T. ,Xia,Q. 2013. The situation and counter measures of undergraduate nursing students' employment. Contemporary nursing. (8),14-16(Chinese language journal).

Wallen GR, Mitchell SA, Melnyk B, Fineout-Overholt E, Miller-Davis C, Yates J, Hastings C. Implementing evidence-based practice: effectiveness of a structuredmultifaceted mentorship programme. Journal of Advanced Nursing,Dec; 66(12):2761-71.

Wanberg C R, Welsh E T, Hezlett S A. ,2003. Mentoring research: A review and dynamic process model. Research in Personnel \& Human Resources Management, 22(03):39-124. 
Wang, Z. H. , 2013, Development of competency inventory of teaching and evaluation of core competency of clinical nursing teachers for undergraduate students (Master's thesis). Shandong University, Jinan City, P. R. China (Chinese language journal).

Weng R H, Huang C Y, Tsai W C, et al. ,2010. Exploring the impact of mentoring functions on job satisfaction and organizational commitment of new staff nurses. Bmc Health Services Research, 10(1):240.

Wu, M. L. , 2010. Statistical analysis practice: Spss operation and Application. fourthed ,Chongqing University Press, China.

Zhao R, Chen YH, Yu HT, Xiao L, Wen J, Yeh TP. , 2017. Psychometric Characteristics of the Clinical Nursing Mentors' Behavior Scale. Hu Li ZaZhi. Aug; 64(4):53-62. (Chinese language journal)

Zhou, M. , 2009. An investigation and analysis of nursing interns' demands for clinical nursing education. Nursing and Rehabilitation. 9, 793-794(Chinese language journal). 
*Manuscript (Clean copy) without title page
Click here to view linked References
Validation of Mentor's Behavior Scale among mentors *Manuscript (Clean copy) without title page
Click here to view linked References
Validation of Mentor's Behavior Scale among mentors

*Manuscript (Clean copy) without title page
Click here to view linked References
Validation of Mentor's Behavior Scale among mentors

*Manuscript (Clean copy) without title page
Click here to view linked References
\[ \text { Validation of Mentor's Behavior Scale among mentors } \]

(1)

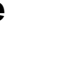

*Manuscript (Clean copy) without title page
Click here to view linked References
Validation of Mentor's Behavior Scale among mentors

*Manuscript (Clean copy) without title page
Click here to view linked References
Validation of Mentor's Behavior Scale among mentors

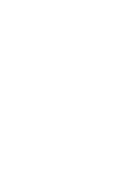

.

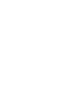

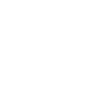

(1)

(1)

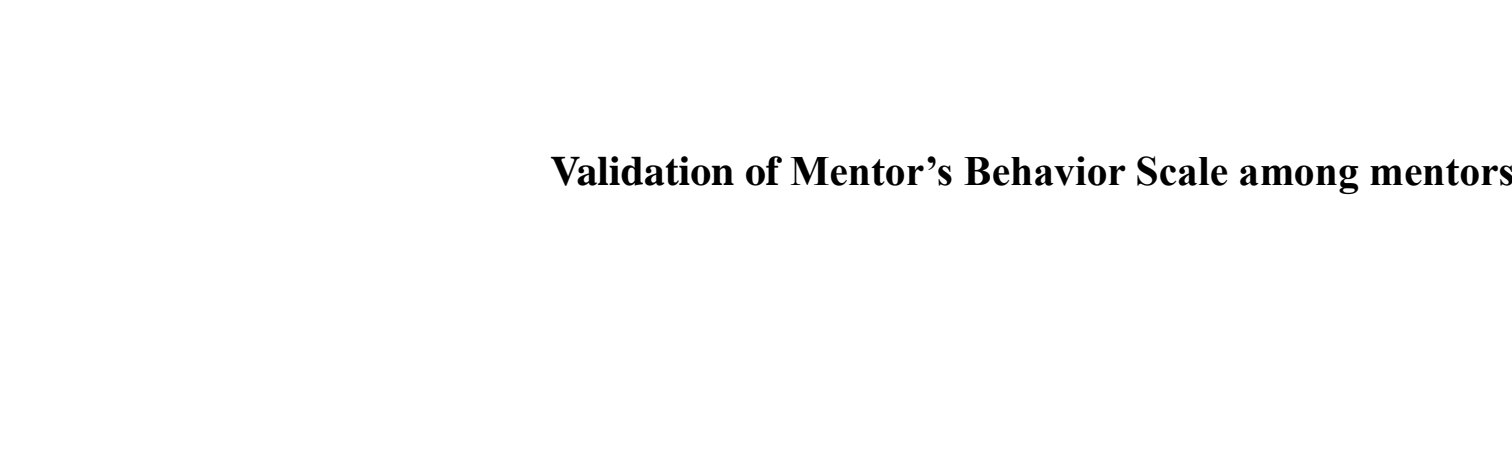

(2)

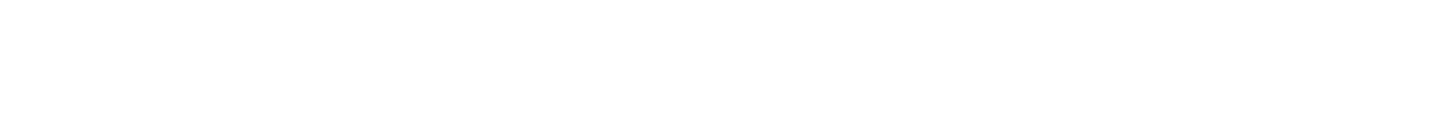

(1)

.

(1)

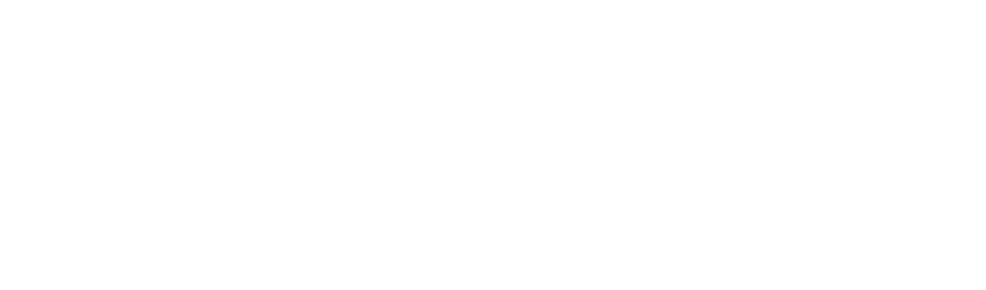


Background: The Mentor's Behavior Scale was developed and validated initially among nursing students by assessing the importance of mentors' behaviour, showing satisfactory psychometrics and the potential to match mentors with students according to students' expectation.

Objectives: This study aims to test the discriminant validity and the structure of the Mentor's Behavior Scale among mentors to assess mentors' performance.

Design: A cross-sectional survey was applied in the study.

Setting: Data were collected from mentors in seven hospitals in north, south, southwest China in 2016 and 2017.

Participant: 871 mentors participated in this study.

Methods: Purposeful sampling and online survey was used.

Results: Three factors (to guide personal growth, promote professional development, and provide psychosocial support) were identified by exploratory factor analysis. The cumulative contribution of variance was $61.03 \%$. The Cronbach's alpha coefficient of the scale was 0.85 , and those of the three subscale's were $0.84,0.72$, and 0.74 . The results of discriminant validity showed that mentors who received training and who liked mentoring students scored higher in mentoring behavior.

Conclusion: Mentors considered that mentoring behavior were to guide students' personal growth, promote professional development and provide them with psychosocial support. It will be useful to apply The Mentor's Behavior Scale among mentors to guide and evaluate their behaviors. 
Key words: nursing; mentors' behavior; guiding personal growth; promoting professional development; psychosocial support 


\section{Highlights}

-A three-dimensional mentor's behaviour model (to guide personal growth, promote professional development, and provide psychosocial support) was identified among mentors.

- This study showed the potential that the Mentor's Behavior Scale could be used among mentors to guide and assess their performance.

-The MBS scale shows the ability to distinguish different level ofmentoring performance. 


\section{Introduction}

Mentorship has been adopted in clinical nursing education in China, but it is developing relatively slower than that of western countries (Chen et al, 2016). Mentors may not perform properly as educators to support, guide and assess nursing students (Eddins et al., 2011). Studies (Heet al., 2011; Yiet al., 2013) report that some nursing students lost their interests in nursing during their time in clinical placement. The reasons include reality shock, negative experience, such as being tense with patients, lack of confidence in skills and knowledge and not being clear about professional prospects. These difficulties suppose to be managed successfully, given ideal mentorship. Therefore, it is necessary for mentors to understand how they should behave to improve the quality of mentorship.

\section{Background}

To guide, standardize and evaluate the behavior of mentors in China, a suitable instrument is essential. The Mentor's Behavior Scale (MBS) was developed through a literature review and online focus group interview by the research group in 2014 and was validated in Chinese Nursing Students (Chen et al, 2016; Chen et al, 2018). The students were asked to measure the importance of each behavior and the results showed a three-factor structure: promoting professional development, facilitating learning and psychosocial support, satisfactory psychometrics and the potential to match mentors with students according to students' expectation using the MBS. The 
structure of this scale was confirmed later in nursing students by asking them the performance of their mentors using confirmatory factor analysis (Chen et al, 2018).However, further validation is necessary to apply this scale among mentors to guide and assess their own performance and to diagnose the weakness and find the training needs. The reason is that the population mentor might be different from students and they may perceive mentorship variously and the psychometrics of a scale is relevant to the population it is tested (Streiner and Norman, 2008).

Therefore, a study aimed to validate the mentors' behaviour scale among mentors to provide the potential of this scale to be used by mentors to guide and evaluate their mentoring behavior was carried out. It showed that the content validity index of MBS among mentors was 0.91 , the test-retest reliability was 0.89 (ICC $=0.89)$. Three factors (guiding personal growth, professional development, psychosocial support) including 23 items were identified, explaining $50.99 \%$ of total variance and published in a Chinese journal (Zhao et al, 2017). While the variance explained was low, other validity, such as discriminant validity was not reported. This study aims to verify the discriminant validity and to obtain a simplified and stable structure using an enlarged sample size.

\section{Methods}

3. 1. Design

A cross-sectional study using an online survey was employed.

\section{2 Instrument}


The MBS was used in this study, which followed a three-dimensional model of mentor's behavior generated through a literature review. The development and validation among nursing students were reported by Chen (2016). In a previous study, A three-dimensional model of mentors' behavior (professional development, psychosocial support and facilitating learning) was identified through exploratory factor analysis and Mokken scale analysis and confirmed among nursing students. (Chen et al. ,2016, Chen et al, 2018).

\section{3. Participants and data collection}

Purposeful sampling was used and 858 mentors from hospitals in Beijing, Shenzhen, Kunming, Sichuan representing mentors in north, west and south of China completed an online survey to explore the structure of mentors' behavior. Questionnaires were selected through the Questionnaire Star, a Chinese online survey tool. In each hospital, there was a research cooperator and they sent internet link to head nurses and then the head nurses sent it to mentors on wards. Each device (cell phone, computer) or each account is allowed only to complete one questionnaire. Mentors were asked to rate the frequency with which they performed the mentoring behaviour and they responded on a 5-point Likert scale (1-5) from 'never' to 'always'. The selection criterion of mentors was that they must have more than one years' experience of continuous mentoring nursing students.

According to the requirements of exploratory factor analysis, the sample should not 
be less than 430 (Ferguson and Cox,1993). In this study, 871mentors responded. The time of completing the questionnaire was monitored and those taking less than 3 minutes were excluded as these were considered to lack motivation to complete the questionnaire carefully. In total, 13 cases were excluded and 858questionnaires were entered into the data analysis.

\section{4 Data Analysis}

The data was at first analyzed using descriptive statistics. Data distribution was tested for normality and homoscedasticity, using the Kolmogorov-Smirnov and Levene tests, respectively. The tests revealed a normal distribution of the data. The construct validity of the instrument was analyzed using explorative factor analysis and the reliability of each of the sub-dimensions was analyzed using Cronbach's alpha coefficient. The discriminant validity was calculated by using ANOVA and independent sample $t$ test. SPSS 22. 0was used in data analysis.

\section{5 Ethics}

The study was approved by the ethics committee of the Affiliated Hospital of Southwest Medical University in China and permission was acquired from seven hospitals in China. Consent statement was explained to participants before they completed the questionnaires that their information could not subsequently be withdrawn but that the confidentiality was protected. No personal information was 
collected.

\section{Results}

4. 1Demographic Information

The demographic information of mentors participated in the survey is shown in Table

1. The majority of them were female $849(98.95 \%)$ and the age ranges from 23 to 54

(31. $57 \pm 7.18)$ years old

\section{2 Structure of mentors' behaviour among mentors}

The exploratory factor analysis results show that the initial sampling suitability KMO value was 0. 97 and Bartlett 's spherical test value was $X^{2}(903)=17207.67,(p<0$. 001)both indicated the correlation coefficients among all the items are large enough to do EFA (Wu, 2010). Principal component analysis (PCA) was selected for this study. Because the number of items was over 40 and some communalities were below 0 . 4,based on eigen values $>1$, there were 6 factors, which probably overestimated the number of factors (Field, 2009). While the scree plot showed that there might be three or four factors. Under this condition, Monte Carlo parallel analysis for Principal Component Analysis (MCPA) was used to decide the number of factors to extract. Finally, three factors were decided. Both orthogonal rotation and oblique rotation were tried. The orthogonal rotation gave a simpler solution and the correlation coefficient between the factors was less than 0.3 . Accordingly, varimax rotation was selected in this study. Items that met the following conditions would be deleted one by 
one: items with loading below 0.6 , cross loading over 0.4 , and the absolute value difference between two maximum cross loading $<0.2$. This process was repeated until a simple structure appeared where loadings were maximized on presumptive factors and minimized on the others.

Principal component analysis was carried out on 43 items (The questionnaire had originally 46 items, and three items were deleted after content validity analysis (Zhao, et la, 2017) with varimax rotation. A three-factor structure with 12 items (four items four each factor) was identified, explaining $61.03 \%$ of the variance. The three factors were named as: Guide Personal Growth (GPG), Professional Development (PD), and Psychosocial Support (PS), according to their contents. Eigenvalue and percentage of explained common variance are shown in Table 2 . The communality and factor loading matrix is shown in Table 3. The scree plot is shown in Figure 1.

\section{3 Internal Consistency Reliability}

The Cronbach alpha coefficient of the total scale was 0.85 and those of the three subscales were $0.84,0.72$, and 0.74 , respectively.

\section{4 Discriminant Validity}

Comparing the difference in scores between groups having mentorship training experience or not, and attitude towards mentoring students, the results showed that the score of trained group was higher and the scores of groups holding different levels of favoring mentorship differed (Table 4). 


\section{Discussion}

This cross-sectional study showed an identical structure of MBS identified in the previous study (Zhao et al, 2017) and tested the discriminant validity among mentors, while this study revealed a model with 12 items, which explained more variance $(61 \%)$ than in a previous study.

While the structure model is not consistent completely with that observed in nursing students, with two same factors: to promote professional development, psychosocial support and one different factor: to guide personal growth instead of to facilitate learning (Chen et al, 2016, Chen et al, 2018). This may be due to the reason that students and mentors perceive mentorship slightly different from each other as psychometrics is closely related to the population tested instead of intrinsic property of a measurement tool (Streiner and Norman, 2008). Mentors may consider mentorship based on a one-to- one relationship, individualized teaching model, therefore to lead students' individual development and growth is an inseparable part of their responsibility. But students may think more about learning, expecting mentors could help with their study, as they are under the pressure of passing all sorts of exams, which may have not much influence over mentors.

Factor 1- Guide Personal Growth including concepts, for instance, personal development, discussing learning goals, stimulating students' potential. The factor reflects that mentors attach importance to the students' individualized education in the "one-to-one" teaching process and take guiding students' personal growth as an 
important aspect of mentoring. Usually, nursing students in China are at the early adult transition stage (17-22 years old), and the structure of their lives are undergoing rapid change. They are moving away from adolescence and family life, and need to build new relationships with patients, mentors and other staff in clinical practice. In addition, the pressure of employment and how to deal with the various relationships in their future work independently are also imposed on them. They may feel anxiety and pressure due to ill-preparation for the new adult world (Levinson, 1986). As a "one-to-one" instructor, a mentor has a close relationship with students, understands students' problems and needs, and knows more about the prospects of the nursing. According to the characteristics of students, mentors set individualized learning goals with students, adopt appropriate teaching methods, which can stimulate enthusiasm and improve effects of learning and contribute to personal growth of students (Zhou, 2009).

Critical thinking scores the lowest in this study, as in Chen's (2016) study. Critical thinking is unanimously recognized as a necessary thinking skill that a nurse should have in data appraisal, analysis and patient care decision-making (Sullivan, 2012). The results suggest that proper guidance and training are imperative (Sullivan, 2012).

Factor 2-Professional Development accounts including concepts such as showing decision making in nursing, encouraging evidence-based practice, the legal issues involved in nursing, giving student an objective and comprehensive evaluation. This factor exists both in the validation of students and in mentors, which suggest clinical practice is a key transitional period from a student to a nurse. Mentors play a pivotal role to make this transition smoothly, that is to say to improve students' professional 
development. But in students' sample, the item" to show a positive image" had the heist loading on the factor (Chen et al, 2016), while in mentors the item "show student how to make decisions on patient care" shared the largest loading. The difference may suggest that mentors are experienced in nursing and perceive that the essence of nursing care is to make proper decision, while students are new to nursing real picture and are incline to be influenced by negative image and behaviour presented by their mentors, and they need positive encouragement to take nursing role as their specialty in the future.

In clinical mentoring, mentors promote the professional development of nursing students by imparting important knowledge and skills in nursing work. Other studies have also emphasized that clinical teachers should have a high level of professional competence (Wang 2013; Gonget al,2003;Knox 1985), but this factor has the lowest scores in this survey, especially for the item 'evidence-based practice'. Some research and training programs should be conducted to enhance mentors' knowledge and skills about it (Wallen et al., 2010)

Factor 3-Psychosocial support includes concepts about being warm and friendly, respect, support and encouragement, role model for students, possessing the highest mean scores. Trust and respect from mentors and being a good role model for students could help students try to imitate the mentor's behavior in mentorship (role modeling) and can then enhance their expertise (Wanberg et al,2003). In addition, it would facilitate the mentee's adaptation to nursing jobs and nursing environments (Weng et 
al, 2010).

This factor has been identified both in nursing students and mentors, but there is some inconsistency. As for students the item "to be treated as a learner other than free human power" was selected to be the first one of this factor (Chen et al, 2016). However, this item was not endorsed highly by mentors; instead the item "to be friendly and warm with students" was the most highly endorsed. This may due to mentors and students valuing different behaviours or the questions asked are different between students and mentors: in students, the importance of behaviour was asked (Chen,et al 2016) while in this study among mentors the frequency of their mentoring behavior was questioned.

The total reliability of the study scale and the three factors were all greater than 0.7 , indicating that the scale and the three facets have good homogeneity, the extracted factor structure was reliable, and the correlation between all items was good.

The results of discriminant validity showed that mentors who have received training and who likes mentoring students have higher scores, suggesting that the scale can detect different levels of mentoring performance, particularly according to mentors'different extents of liking mentoring students. This reveals that education administrators should consider the mentor's attitude towards mentoring when selecting mentors besides clinical competence. At the same time, the specially 
designed mentor program helps to lead to a more positive attitude towards mentoring and a positive effect on mentor functioning is pivotal (Smedley, 2010).

\section{Conclusion}

The Mentors' Behavior Scale showed the three-factor behaviour structure has been observed. This study expanded the use of MBS from rating nursing students expectation of mentorship to assessing mentoring performance by mentors themselves and provided the possibility to use the MBS among mentors to guide and assess their behaviours.

\section{Conflict of Interests}

None declared.

\section{Funding}

No special source of funding. 


\section{References}

Chen, Y. , Watson, R. , Hilton, A. , 2016. An exploration of the structure of mentors' behavior in nursing educationusing exploratory factor analysis and Mokken scale analysis. Nurse Education Today. 40,(161-167).

Chen Y, Watson R, Hilton A. , 2018. The structure of mentors' behaviour in clinical

nursing education: Confirmatory factor analysis. Nurse Education Today. Jun

26;68:192-197.

Chen, Y. H. , 2016. Developing and validating a scale to study mentors'behaviour in nursing education (Unpublished doctor's thesis). University of Hull, Hull, UK.

Eddins, E. E. , Hu ,J. , Liu, H. , 2011. Baccalaureate nursing education in China: issues and challenges. Nursing Education Perspectives. 32(1),30-33.

Field, A. , 2009. Discovering statistics using SPSS. third ed. Sage publications, London.

Gong, Y. H. , Wang, Y. , Lu, H. , \& Zheng, X. ,2003, A survey of effective teaching behaviors of clinical teachers. Chinese Journal of Nursing, 38(1), 10-13(Chinese language journal).

He, J. Y. , Jiang, X. Y. ,Jin, S. ,2011. A survey on the attitude towards employment in undergraduate nursing students. Journal of Chinese Nursing Management. 11(7), 75-77(Chinese language journal).

Knox, J. E. ,\&Mogan, J. (1985). Important clinical teacherbehaviours as perceived by 
university nursing faculty, students and graduates. Journal of Advanced Nursing, 10(1), 25-30.

Levinson, D. J. , 1986. A conception of adult development. American Psychologist. 41(1), 3-13.

Smedley A, Morey P, Race P. ,2010. Enhancing the knowledge, attitudes, and skills of preceptors: an Australian perspective. Journal of Continuing Education in Nursing, 41(10):451.

Streiner, D. L. , Norman, G. R. , 2008. Health measurement scales: A practical guide to their development and use. fourth ed. Oxford University Press, Oxford.

Sullivan E A. , 2012. Critical thinking in clinical nurse education: Application of Paul's model of critical thinking. Nurse Education in Practice, 12(6):322-7.

Yi,Y. M. N. ,Qiu,H. L. ,Liu,L. ,Li,J. N. ,Liang,T. T. ,Xia,Q. 2013. The situation and counter measures of undergraduate nursing students' employment. Contemporary nursing. (8),14-16(Chinese language journal).

Wallen GR, Mitchell SA, Melnyk B, Fineout-Overholt E, Miller-Davis C, Yates J, Hastings C. Implementing evidence-based practice: effectiveness of a structuredmultifaceted mentorship programme. Journal of Advanced Nursing,Dec; 66(12):2761-71.

Wanberg C R, Welsh E T, Hezlett S A. ,2003. Mentoring research: A review and dynamic process model. Research in Personnel \& Human Resources Management, 22(03):39-124. 
Wang, Z. H. , 2013, Development of competency inventory of teaching and evaluation of core competency of clinical nursing teachers for undergraduate students (Master's thesis). Shandong University, Jinan City, P. R. China (Chinese language journal).

Weng R H, Huang C Y, Tsai W C, et al. ,2010. Exploring the impact of mentoring functions on job satisfaction and organizational commitment of new staff nurses. Bmc Health Services Research, 10(1):240.

Wu, M. L. , 2010. Statistical analysis practice: Spss operation and Application. fourthed ,Chongqing University Press, China.

Zhao R, Chen YH, Yu HT, Xiao L, Wen J, Yeh TP. , 2017. Psychometric Characteristics of the Clinical Nursing Mentors' Behavior Scale. Hu Li ZaZhi. Aug; 64(4):53-62. (Chinese language journal)

Zhou, M. , 2009. An investigation and analysis of nursing interns' demands for clinical nursing education. Nursing and Rehabilitation. 9, 793-794(Chinese language journal). 
Table 1 Demographic Information

\begin{tabular}{|c|c|c|c|}
\hline & & Frequency & Percentage \\
\hline \multirow[t]{4}{*}{ Length of mentoring } & $1 \sim 2$ years & 288 & 33.57 \\
\hline & $3 \sim 5$ years & 229 & 26.69 \\
\hline & $6 \sim 10$ years & 150 & 17.48 \\
\hline & $>10$ years & 191 & 22.26 \\
\hline \multirow{6}{*}{$\begin{array}{l}\text { Education } \\
\text { background }\end{array}$} & & 8 & 0.93 \\
\hline & 3-year diploma & & \\
\hline & Associate degree & 176 & 20.51 \\
\hline & Degree & 654 & 76. 22 \\
\hline & Master & 19 & 2.21 \\
\hline & Doctorate & 1 & 0.12 \\
\hline \multirow[t]{5}{*}{ Department } & Internal medicine & 297 & 34.62 \\
\hline & Surgery & 346 & 40.33 \\
\hline & $\begin{array}{l}\text { Obstetrics \& } \\
\text { Gynecology }\end{array}$ & 56 & 6.53 \\
\hline & Pediatrics & 40 & 4.66 \\
\hline & Others & 119 & 13. 87 \\
\hline \multirow{2}{*}{$\begin{array}{l}\text { Mentorship training } \\
\text { experience }\end{array}$} & Yes & 503 & 58.62 \\
\hline & No & 355 & 41.38 \\
\hline \multirow{4}{*}{$\begin{array}{l}\text { Attitude towards } \\
\text { mentoring }\end{array}$} & Dislike & 23 & 2.68 \\
\hline & Be indifferent & 317 & 36.95 \\
\hline & Like & 460 & 53.61 \\
\hline & Very like & 58 & 6.76 \\
\hline
\end{tabular}


Table 2 Eigenvalue and Percentage of explained common variance

\begin{tabular}{cccc} 
& & Percentage of & Accumulated \\
& & Explained common & percentage of explained \\
Factor & Eigenvalue & variance & common variance \\
\hline 1 & 4.61 & 38.38 & 38.38 \\
3 & 1.58 & 13.17 & 51.54 \\
\hline
\end{tabular}


Table 3Principal component analysis with varimax rotation

\begin{tabular}{|c|c|c|c|c|c|}
\hline \multirow{2}{*}{ Items } & \multirow{2}{*}{ Mean \pm SD } & \multirow{2}{*}{$\begin{array}{c}\text { Commonalit } \\
\mathrm{y}\end{array}$} & \multicolumn{3}{|c|}{ Factorloading } \\
\hline & & & Factor1 & Factor2 & Factor3 \\
\hline 35. guide student's personal development & $3.83 \pm 0.93$ & 0.71 & 0.81 & 0.14 & 0.17 \\
\hline $\begin{array}{l}\text { 36. stimulate student to provide the best } \\
\text { possible care }\end{array}$ & $3.95 \pm 0.87$ & 0.68 & 0.75 & 0.26 & 0.21 \\
\hline 41. discuss learning goals with student & $3.74 \pm 0.99$ & 0.65 & 0.75 & 0.19 & 0.21 \\
\hline $\begin{array}{l}\text { 26. develop student critical thinking } \\
\text { ability. }\end{array}$ & $3.59 \pm 0.97$ & 0.61 & 0.75 & 0.22 & 0.06 \\
\hline $\begin{array}{l}\text { 7. show student how to make decisions on } \\
\text { patient care }\end{array}$ & $3.70 \pm 0.90$ & 0.64 & 0.32 & 0.73 & 0.10 \\
\hline $\begin{array}{l}\text { 6. encourage the use of evidence-based } \\
\text { practice }\end{array}$ & $3.43 \pm 1.04$ & 0.59 & 0.37 & 0.68 & 0.03 \\
\hline $\begin{array}{l}\text { 1. give student an objective and } \\
\text { comprehensive evaluation }\end{array}$ & $3.92 \pm 0.86$ & 0.51 & -0.07 & 0.67 & 0.22 \\
\hline $\begin{array}{l}\text { 5. make student aware of the legal issues } \\
\text { involved in nursing }\end{array}$ & $3.83 \pm 0.96$ & 0.55 & 0.32 & 0.67 & 0.05 \\
\hline 39. be warm and friendly to student & $4.59 \pm 0.55$ & 0.67 & 0.12 & 0.05 & 0.81 \\
\hline 14. respect student & 4. $66 \pm 0.49$ & 0.56 & -0.06 & 0.19 & 0.72 \\
\hline 31. support and encourage student & $4.45 \pm 0.60$ & 0.60 & 0.33 & 0.11 & 0.70 \\
\hline 43. be a good role model for students & 4. $41 \pm 0.654$ & 0.56 & 0.36 & 0.07 & 0.65 \\
\hline
\end{tabular}


Figure 1 Screen Plot

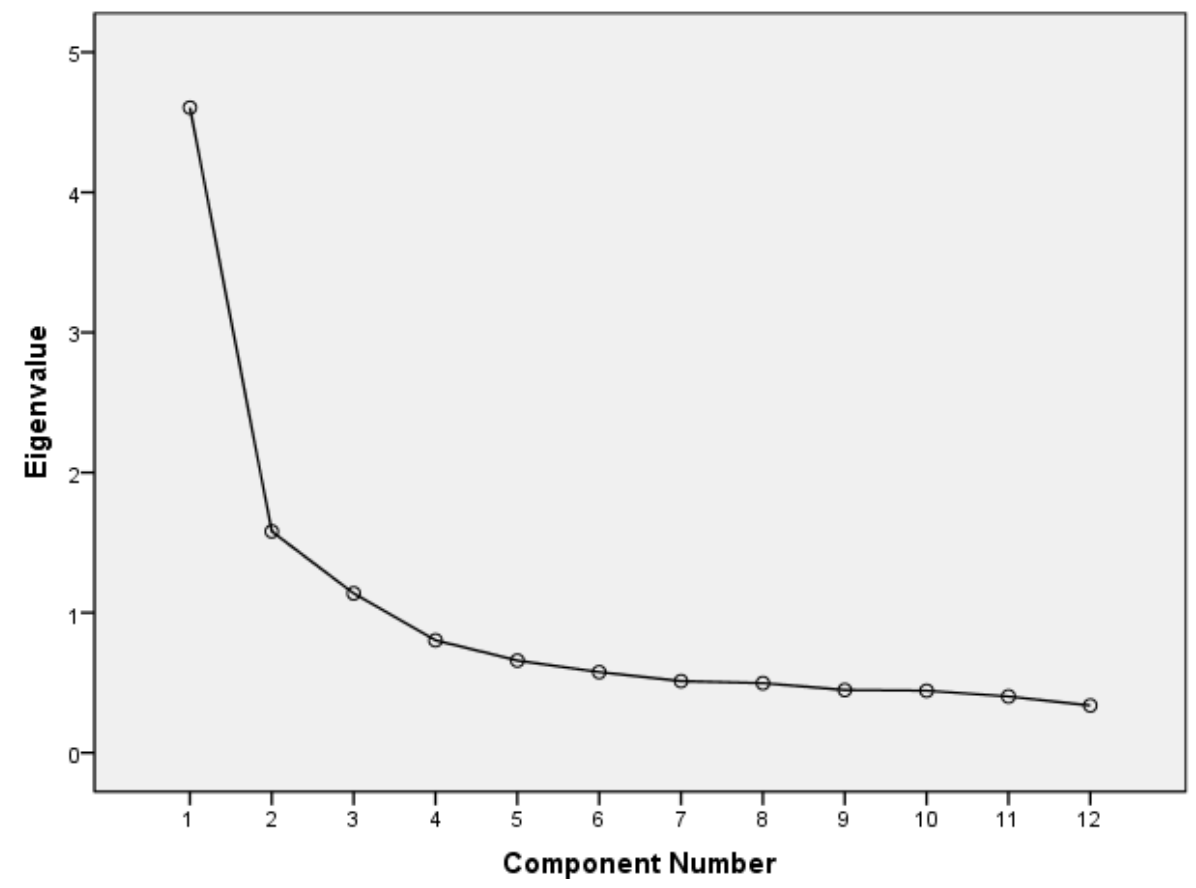


Table 4 Discriminant Validity

\begin{tabular}{|c|c|c|c|c|c|}
\hline & & Groups & Mean \pm SD & $\mathrm{F}$ & $t$ \\
\hline \multirow[t]{2}{*}{ Mentorship } & training & & & & 0. \\
\hline & & Yes & $49.23 \pm 5.74$ & 6.51 & \\
\hline \multirow[t]{2}{*}{ experience } & & & & & 00 \\
\hline & & No & 46. $48 \pm 6.36$ & & \\
\hline \multirow[t]{2}{*}{ Attitude } & towards & & & & 0. \\
\hline & & Dislike & $44.09 \pm 7.82$ & 22.57 & \\
\hline \multirow[t]{4}{*}{ mentoring } & & & & & 00 \\
\hline & & Be indifferent & 46. $49 \pm 6.09$ & & \\
\hline & & Like & $48.91 \pm 5.85$ & & \\
\hline & & Extremely like & $52.02 \pm 4.72$ & & \\
\hline
\end{tabular}

